\title{
Dye-Sensitized Solar Cells based on dimethylamino- $\pi$-bridge- pyranoanthocyanin dyes
}

\author{
Ana Lucia Pinto, ${ }^{a}$ Hugo Cruz, ${ }^{\mathrm{a}}$ Joana Oliveira, ${ }^{\mathrm{b}}$ Paula Araújo, ${ }^{\mathrm{b}}$ Luis Cruz, ${ }^{\mathrm{b}}$ Vânia Gomes, ${ }^{\mathrm{b}}$ Cassio P. \\ Silva, ${ }^{\mathrm{c}}$ Gustavo T. M. Silva, ${ }^{\mathrm{c}}$ Tiago Mateus, ${ }^{\mathrm{d}}$ Giuseppe Calogero, ${ }^{\mathrm{e}}$ Victor de Freitas, ${ }^{\mathrm{b}}$ Frank H. Quina,${ }^{\mathrm{c}}$ \\ Fernando Pina, ${ }^{a}$ A. Jorge Parola, ${ }^{a}$ J. Carlos Lima ${ }^{a}, *$ \\ ${ }^{a}$ LAQV-REQUIMTE, Departamento de Química, Faculdade de Ciências e Tecnologia, Universidade \\ NOVA de Lisboa, 2829-516 Caparica, Portugal. \\ ${ }^{b}$ LAQV-REQUIMTE, Departamento de Química e Bioquímica, Faculdade de Ciências, Universidade \\ do Porto, Rua do Campo Alegre, 687, 4169-007 Porto, Portugal. \\ ${ }^{c}$ Instituto de Química, Universidade de São Paulo, Av. Lineu Prestes 748, Cidade Universitária, São \\ Paulo 05508-000, Brazil \\ ${ }^{d}$ UNINOVA CEMOP, Faculdade de Ciências e Tecnologia, Universidade NOVA de Lisboa, 2829- \\ 516 Caparica, Portugal. \\ ${ }^{e}$ CNR, Instituto per i Processi Chimico-Fisici, Sede di Messina, Salita Sperone, C. da Papardo, I- \\ 98158 Faro Superiore Messina, Italy.
}

Keywords: bio-inspired DSSCs, pyranoflavylium dyes, $\pi$-bridge, -OH linkage, amino linkage, dual-point anchorage

\begin{abstract}
The pyranoanthocyanins present in red wine display great potential as photosensitizers in bio-inspired Dye-Sensitized Solar Cells (DSSCs). Following a biomimetic approach, a series of amino- $\pi$-bridgepyranoanthocyanin derivatives were employed as dye sensitizers in DSSCs. The dimethylamine group was selected to take advantage of its electron-donor character and the possibility of 'dual-mode anchoring' (-OH vs. dimethylamino) to titanium dioxide. The increase in $\pi$-conjugation via insertion of $\mathrm{C}=\mathrm{C}$ bonds affected molecule flexibility, electron-donor ability and the $\mathrm{pH}$-dependent equilibria of the pyranoanthocyanin derivatives. The current $v s$. potential properties of photoanodes using these
\end{abstract}


dyes pointed to essential features of the relationship between power conversion efficiency and dye structure. These included the influences of the dimethylamine group, of $\pi$-conjugation and of substitution in ring $\mathrm{B}$ on the adsorption of the dyes to $\mathrm{TiO}_{2}$ and on the overall performance of the DSSCs prepared from them with and without added acid. An overall efficiency of $2.55 \%$ was obtained for the best performing compound, 4-(dimethylamino)-cinnamyl-pyranocyanidin-3-O-glucoside (JO3), which consolidates the importance of this family of compounds as potential dye-sensitizers for DSSC applications.

\section{Introduction}

Anthocyanins constitute a major polyphenolic family of natural pigments responsible for the colors seen in a broad variety of flowers, fruits, vegetables and roots. These compounds have characteristic physicochemical properties that give them their stability and unique color palette. From yellow, to red and blue, anthocyanins are highly reactive compounds that can change their color by means of structural variations dependent on external stimuli such as $\mathrm{pH}$, temperature and light. (Pina, 2014) Anthocyanins, primarily malvidin-3-O-glucoside (oenin), are the major dyes responsible for the redpurple colors of Vitis vinifera grapes and of young red wines. (Da Silva et al., 2018; Oliveira et al., 2017; Sousa et al., 2017) During red wine maturation, the content of free anthocyanins decreases due to chemical reactions with yeast metabolic products, amongst others. These reactions result in the transformation of anthocyanins into more complex structures such as pyranoanthocyanins, which give aged red wine its characteristic burgundy color. Pyranoanthocyanins are particularly interesting due to their contributions to the taste (e.g. astringency), antioxidant capacity, and the health benefits of moderate red wine consumption. (Da Silva et al., 2018; García-Estévez et al., 2017; Oliveira et al., 2017) Furthermore, since these compounds present no apparent hydration and only undergo protonation/deprotonation reactions in water, they present greater color stability than their anthocyanin precursors. (Cruz et al., 2017; Oliveira et al., 2009; Sousa et al., 2017) Hence, these pigments are interesting for a wide range of potential applications from food colorants to energy applications such as Dye-Sensitized Solar Cells (DSSCs). (Czerney et al., 1995; Roque et al., 2002)

Tennakone and co-workers were the first to use cyanidin in a dye-sensitized nanocrystalline solar cell (Tennakone et al., 1997), while Grätzel and co-workers were the first to apply anthocyanin dyes extracted from blackberries (cyanidin-3-glucoside) in a DSSC, obtaining a conversion yield of $0.56 \%$ (Cherepy et al., 1997). Both pioneering works paved the way for sustainable DSSCs based on renewable resources. (Calogero et al., 2019; Güzel et al., 2018; Hug et al., 2014; Mohiuddin et al., 
2018; Richhariya et al., 2017; Sharma et al., 2018) In fact, some natural flavylium derivatives, such as cyanidin, delphinidin and petunidin, can efficiently anchor to $\mathrm{TiO}_{2}$ through the catechol unit in ring $\mathrm{B}$, but do not possess the donor-acceptor pattern optimized for efficient electron transfer. Following a bio-inspired strategy one can prepare quasi-natural biomimetic compounds with the adequate structural modifications. Employing simple, non-toxic and environmentally safe synthetic procedures, it is possible to design and synthesize compounds with properties similar to those of natural occurring anthocyanins while tailoring desirable traits such as energy levels, absorption properties and electron-donor moieties. In fact, replacement of the glucose and the hydroxyl group at position 5 of ring A of cyanidin-3-glucoside by hydrogen, and of the hydroxyl group at position 7 by a diethylamino group led to a DSSC with a conversion yield of $2.2 \%$ and, upon device assembly optimization, an efficiency of $3.0 \%$ was achieved for a DSSC containing this compound (7diethylamino-3',4'-dihydroxyflavylium, Scheme 1). (Calogero et al., 2017, 2013)

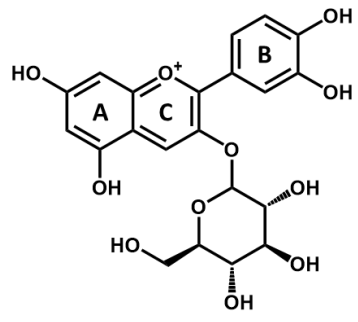

(a)

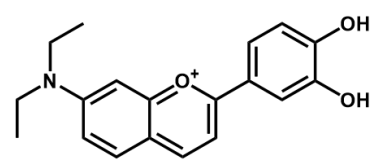

(b)

Scheme 1. Chemical structures of cyanidin-3-glucoside (a) and the 7-diethylamino-3',4'-dihydroxyflavylium cation (b).

On the one hand, these results emphasize the importance of looking to Nature as a source of inspiration when designing new molecules for DSSC application. On the other hand, they put a focus on the importance of the presence of a dialkylamino substituent in the dye structure. In flavylium compounds and pyranoanthocyanins, the dimethylamino group causes a bathochromic shift of the long-wavelength absorption maximum, leading to the formation of bluish compounds, a requirement much appreciated in dyes for DSSC applications. (Oliveira et al., 2017; Schwarz and Winterhalter, 2003; Tron et al., 2016) In addition to extending the dye absorbance towards the red region of the visible spectrum, the dialkylamine group can serve as a strong electron-donating moiety in a D- $\pi$-A (Donor-[ $\pi$-bridge]-Acceptor) molecular motif. (Mahmood, 2016) 
$D-\pi-A$ systems are believed to mediate effective intramolecular charge transfer from the donor (D) to the acceptor (A) moiety of the molecule via a $\pi$-conjugated unit. Appropriate $\pi$-conjugation between $\mathrm{D}$ and $\mathrm{A}$ can broaden the absorption wavelength range and increase the molar extinction coefficient of the molecules. (Mahmood, 2016; Toan et al., 2019; Zhang et al., 2019) The insertion of $\mathrm{C}=\mathrm{C}$ bonds is one way to extend the $\pi$-conjugation and has been reported to improve the overall efficiency of devices by extending the conjugation in the dye chromophore. (Teng et al., 2010) Nevertheless, the nature of the $\pi$-segment can also affect the energetics and the kinetic characteristics of the $\mathrm{TiO}_{2} /$ dye/electrolyte interface and hence influence the electron injection and regeneration processes. Insertion of $\mathrm{C}=\mathrm{C}$ bonds can result in a less rigid dye molecule, which can contribute to energy losses in the process of electron injection at the dye/ $\mathrm{TiO}_{2}$ interface. (Zhang et al., 2019) Thus, increasing the number of $\mathrm{C}=\mathrm{C}$ bonds without guaranteeing the maintenance/increase of molecular rigidity, may then result in lower power conversion efficiency (PCE) due to competitiveness between electron injection and vibrational relaxation. (Chen et al., 2007; Zhang et al., 2019)

In the flavylium and pyranoanthocyanin families of compounds, further potential effects of an increase in $\pi$-conjugation through $\mathrm{C}=\mathrm{C}$ bonds on the chemical and photochemical stability of these compounds in solution must also be considered. Since the $\mathrm{p} K_{\mathrm{a}}$ of these cations increases upon insertion of $\mathrm{C}=\mathrm{C}$ bonds (Amić et al., 1992; Oliveira et al., 2017), for DSSC applications besides the above mentioned effects, one can also expect a change in the electron donating ability of the dialkylamino group upon increasing the number of $\mathrm{C}=\mathrm{C}$ bonds in the $\pi$-segment.

As mentioned above, along with its light capturing function, the dye plays a crucial role in controlling many of the charge transfer processes that result in the final efficiency of a DSSC device. Aside from the dye $/ \mathrm{TiO}_{2}$ interaction, one must also consider the dye/electrolyte interface. (Clifford et al., 2012) It is known that adsorption/intercalation of certain electrolyte cations, such as $\mathrm{Li}^{+}$, into $\mathrm{TiO}_{2}$ affects not only the semiconductor bandgap, but also the absorption range of the dyes. (Furube et al., 2005) The negative partial charges on the organic dye sensitizer can potentially attract $\mathrm{Li}^{+}$cations, which could in turn facilitate the approximation of $\mathrm{I}_{3}^{-}$, leading to faster recombination between the injected electrons in the $\mathrm{TiO}_{2}$ and the oxidized form of the electrolyte. (Clifford et al., 2012) Thus, the potentially detrimental effects of insertion of $\mathrm{C}=\mathrm{C}$ bonds associated with increased dye flexibility, changes in the electron-donor ability of substituents and facilitation of recombination through interactions with the electrolyte cannot be neglected. (Clifford et al., 2012)

Following up on recent works where pyranoanthocyanin compounds were shown to display great potential as photosensitizers in bio-inspired DSSCs, achieving efficiencies of $1.6 \%$ (Pinto et al., $2019 a, 2019 b)$, in here, we report the investigation of the series of dimethylamino- $\pi$-bridge- 
pyranoanthocyanin derivatives shown in Scheme 2 in the context of their application as sensitizer dyes in DSSCs. The dimethylamino group causes the expected bathochromic shift in the maximum absorbance wavelength of the dyes and enhances its electron-donor ability, as well as potentially participating in 'dual-mode anchoring' (-OH vs. dimethylamino). Furthermore, the consequences of an increase in $\pi$-conjugation through insertion of $\mathrm{C}=\mathrm{C}$ bonds were also studied, along with the concomitant effects on dye flexibility and electron-donor ability of the dimethylamino group. Most works fail to fully grasp the impact of the available prototropic equilibria and the related spectroscopic changes found in this family of compounds in their performance for DSSC applications. Only with this type of comprehensive study of the impact of the degree of protonation of the dyes in their final performance as light absorbers in the devices, one can fully conclude about their potential for energy applications. The current $v s$. potential properties of photoanodes containing these dyes were measured and a relation was established between power conversion efficiency and dye structure, providing insight into the influence of the dimethylamine unit and $\pi$-conjugation on the overall performance of DSSCs based on these dyes.
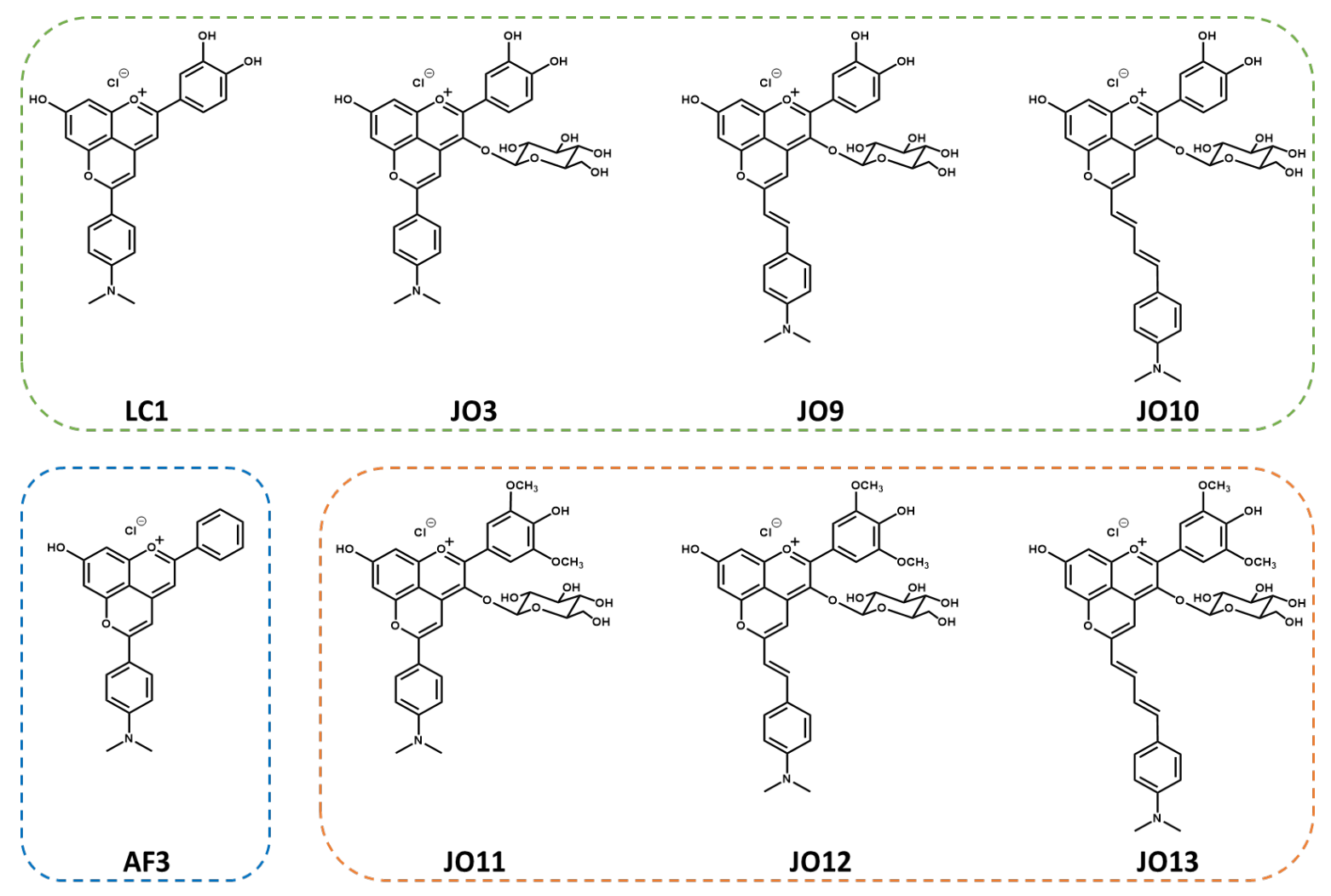

Scheme 2. Chemical structures of the eight pyranoanthocyanin derivatives studied in this work in their cationic form. Ring B substitution highlighted in rectangles: green - cyanidin derivatives; blue - no substitution; and orange - malvidin (oenin) derivatives. 


\section{Experimental (Materials and Methods)}

\subsection{General information and instrumentation}

All solvents and chemicals employed for synthesis and for preparation of samples were of reagent or spectrophotometric grade and were used as received.

Syntheses - The syntheses of compounds LC1 (Cruz et al., 2017), AF3 (Da Silva et al., 2018), JO11 (Schwarz and Winterhalter, 2003), JO12 (Oliveira et al., 2016b) and JO13 (Oliveira et al., 2016a) were performed as previously described. Compounds $\mathbf{J O 3}$ and $\mathbf{J O 9}$ were obtained via the reaction of cyanidin-3-O-glucoside and carboxypyranocyanidin-3-O-glucoside, respectively with 4dimethylaminocinnamic acid by analogy to the procedures reported by Schwarz et al., 2003 (Schwarz and Winterhalter, 2003) and Oliveira et al., 2016 (Oliveira et al., 2016a). JO10 was prepared from the reaction of methylpyranocyanidin-3-O-glucoside with 4-dimethylaminocinnamaldehyde as described in the literature. (Oliveira et al., 2016a)

Physico-chemical characterization of the compounds - Optical measurements: The UV-Vis absorption spectra were recorded in solution in a $1 \mathrm{x} 1 \mathrm{~cm}$ quartz cuvette using a Varian Cary 5000 Spectrometer. The solution spectra were collected between 250 and $850 \mathrm{~nm}$ at room temperature, with a $1 \mathrm{~nm}$ interval, at full slit height, in double beam mode. The absorption spectra of the dyes adsorbed onto $\mathrm{TiO}_{2}$ were measured in a solid sample holder in transmittance mode using a Varian Cary 5000. The titanium oxide film employed for Vis absorption experiments was prepared by doctor blade: two edges of the conductive glass plate (area: $15 \mathrm{~cm} \mathrm{x} 4 \mathrm{~cm}$ ) were covered with strips of an adhesive tape (3 M Magic) and the transparent titania paste (18NR-T, Greatcell Solar) was spread uniformly on the substrate by sliding a glass rod along the tape spacer. The $\mathrm{TiO}_{2}$-coated plates were gradually heated up to $325{ }^{\circ} \mathrm{C}$, then the temperature was increased to $375{ }^{\circ} \mathrm{C}$ in 5 minutes, and afterwards to $500{ }^{\circ} \mathrm{C}$. The plates were sintered at this temperature for $30 \mathrm{~min}$, and finally cooled down to room temperature. Each slide was cut into rectangular pieces (area: $1 \mathrm{~cm} \times 4 \mathrm{~cm}$ ), resulting in slides with a transparent ultrathin $\mathrm{TiO}_{2}$ film with an estimated thickness of about $6 \mu \mathrm{m}$. The $\mathrm{TiO}_{2-}$ coated slides were soaked for $2 \mathrm{~h}$ in an ethanol solution of the dye at a concentration of $0.5 \mathrm{mM}$, at room temperature in the dark. The excess dye was removed by rinsing the photoanodes with the same solvent as that employed for the dye solution. The Vis absorption spectra of the dyes adsorbed to $\mathrm{TiO}_{2}$ were collected between 400 and $850 \mathrm{~nm}$ at room temperature, with a $1 \mathrm{~nm}$ interval, at full slit height, in double beam mode. The absorbance of the assembled DSSCs was also measured in diffuse reflectance geometry, using an STD FL detector and reflection probe from SarSpec, in order to 
confirm the absorption range of the overall assembled cell. The spectra were collected at room temperature, between 400 and $950 \mathrm{~nm}$, using an assembled device with no adsorbed dye as blank (in order to correct for the influence of the absorption by the FTO-layers, $\mathrm{TiO}_{2}$ film, electrolyte and cathode film).

Determination of $p K_{a}$ values: Stock solutions of the pyranoanthocyanin pigments JO3, JO9 and JO10 $(0.1 \mathrm{mM})$ were prepared in $0.1 \mathrm{M} \mathrm{HCl}$ aqueous solution and protected against light. Stock solution of compound AF3 was prepared in $0.1 \mathrm{M} \mathrm{HCl} \mathrm{H}_{2} \mathrm{O}: 0.1 \mathrm{M} \mathrm{HCl}$ ethanol (1:1) solution and kept in the dark. The resulting low $\mathrm{pH}$ value of the stock solutions $(\mathrm{pH} \approx 1)$ ensured that most of the pyranoanthocyanins were in their cationic form (see Scheme 3 ). The thermodynamic acidity constants were determined by spectrophotometric titrations. For each dye, a solution was prepared by sequentially adding $2.5 \mathrm{~mL}$ of $0.1 \mathrm{M}$ aqueous $\mathrm{NaOH}$ solution, $2.5 \mathrm{~mL}$ of universal buffer solution (Küster and Thiel, 1982) at $\mathrm{pH} 1,2.5 \mathrm{~mL}$ of Millipore water and $2.5 \mathrm{~mL}$ of the pyranoanthocyanin stock solution, resulting in a final concentration of each pigment of $0.025 \mathrm{mM}$. Increasing amounts of $1 \mathrm{M} \mathrm{NaOH}$ solution were successively added to the solution, covering the $\mathrm{pH}$ range between 1 and 12. After each addition, the mixture was shaken, a UV-Vis spectrum was recorded, and the $\mathrm{pH}$ was measured with a Radiometer Copenhagen PHM240 pH/ion meter (pH values below 2 and above 12 were calculated from the analytical concentration of $\mathrm{H}^{+}$).

DSSCs fabrication and photovoltaic characterization - The detailed procedure has been described elsewhere.(Pinto et al., 2019b) The conductive FTO-glass (TEC7, Greatcell Solar) used for the preparation of the transparent electrodes was first cleaned with detergent and then washed with water and ethanol. To prepare the anodes, the conductive glass plates (area: $15 \mathrm{~cm} \mathrm{x} 4 \mathrm{~cm}$ ) were immersed in a $\mathrm{TiCl}_{4} /$ water solution $(40 \mathrm{mM})$ at $70^{\circ} \mathrm{C}$ for $30 \mathrm{~min}$, washed with water and ethanol and sintered at $500^{\circ} \mathrm{C}$ for 30 minutes. This procedure is essential in order to improve the adherence of the subsequently deposited nanocrystalline layers to the glass plates, as well as to serve as a 'blockinglayer', helping to block charge recombination between electrons in the FTO and holes in the $\mathrm{I}^{-} / \mathrm{I}_{3}{ }^{-}$ redox couple. Afterwards, the $\mathrm{TiO}_{2}$ nanocrystalline layers were deposited on these pre-treated FTO plates by screen-printing the transparent titania paste (18NR-T, Greatcell Solar) using a frame with polyester fibers having 43.80 mesh per $\mathrm{cm}^{2}$. This procedure, involving two steps (coating and drying at $125^{\circ} \mathrm{C}$ ), was repeated twice. The $\mathrm{TiO}_{2}$-coated plates were gradually heated up to $325^{\circ} \mathrm{C}$, then the temperature was increased to $375^{\circ} \mathrm{C}$ in 5 minutes, and afterwards to $500{ }^{\circ} \mathrm{C}$. The plates were sintered at this temperature for $30 \mathrm{~min}$, and finally cooled down to room temperature. A second treatment with the same $\mathrm{TiCl}_{4} /$ water solution $(40 \mathrm{mM}$ ) was performed, following the procedure previously described. 
This second $\mathrm{TiCl}_{4}$ treatment is also an optimization step that enhances the surface roughness for dye adsorption, thus positively affecting the photocurrent produced by the cell under illumination. Finally, a coating of reflective titania paste (WER2-O, Greatcell Solar) was deposited by screenprinting and sintered at $500{ }^{\circ} \mathrm{C}$. This layer of $150-200 \mathrm{~nm}$ sized anatase particles functions as a 'photon-trapping' layer that further improves the photocurrent. Each anode was cut into rectangular pieces (area: $2 \mathrm{~cm} \times 1.5 \mathrm{~cm}$ ) having a spot area of $0.196 \mathrm{~cm}^{2}$ with a thickness of $15 \mu \mathrm{m}$. The prepared anodes were soaked for $17 \mathrm{~h}$ in an ethanol solution of the dye $(0.5 \mathrm{mM})$, at room temperature in the dark. The excess dye was removed by rinsing the photoanodes with the same solvent as that employed for the dye solution. For the study of the impact of acid addition on the photovoltaic properties of the cells, all the above adsorption process was repeated for each compound with a $0.5 \mathrm{mM}$ solution of the dye prepared in ethanol with $10 \mu \mathrm{L} \mathrm{HClO}_{4}$.

Each counter-electrode consisted of an FTO-glass plate (area: $2 \mathrm{~cm} \times 2 \mathrm{~cm})$ in which a hole $(1.5 \mathrm{~mm}$ diameter) was drilled. The perforated substrates were washed and cleaned with water and ethanol in order to remove any residual glass powder and organic contaminants. The transparent Pt catalyst (PT1, Greatcell Solar) was deposited on the conductive face of the FTO-glass by doctor blade: one edge of the glass plate was covered with a strip of an adhesive tape (3 M Magic) both to control the thickness of the film and to mask an electric contact strip. The Pt paste was spread uniformly on the substrate by sliding a glass rod along the tape spacer. The adhesive tape strip was removed, and the glasses heated at $550{ }^{\circ} \mathrm{C}$ for $30 \mathrm{~min}$. The photoanode and the Pt counter-electrode were assembled into a sandwich type arrangement and sealed (using a thermopress) with a hot melt gasket made of Surlyn ionomer (Meltonix 1170-25, Solaronix SA). The electrolyte was prepared by dissolving the redox couple, $\mathrm{I}^{-} / \mathrm{I}_{2}\left(0.8 \mathrm{M}\right.$ LiI and $\left.0.05 \mathrm{M} \mathrm{I}_{2}\right)$, in an acetonitrile/valeronitrile $(85: 15, \% \mathrm{v} / \mathrm{v})$ mixture. The electrolyte was introduced into the cell via backfilling under vacuum through the hole drilled in the back of the cathode. Finally, the hole was sealed with adhesive tape.

Photoelectrochemical Measurements - Current-Voltage curves were recorded with a digital Keithley SourceMeter multimeter (PVIV-1A) connected to a PC. Simulated sunlight irradiation was provided by an Oriel solar simulator (Model LCS-100 Small Area Sol1A, 300 W Xe Arc lamp equipped with AM 1.5 filter, $100 \mathrm{~mW} / \mathrm{cm}^{2}$ ). The external quantum efficiency (EQE) measurements were performed using a Newport QuantX-300 system, equipped with a Xenon lamp of $100 \mathrm{~W}$, at wavelength intervals of $10 \mathrm{~nm}$ with a nominal illumination spot size of $0.8 \times 1.1 \mathrm{~mm}$. The thickness of the oxide film deposited on the photoanodes and $\mathrm{TiO}_{2}$ slides was measured using an Alpha-Step D600 Stylus Profiler (KLA-Tencor). 


\section{Results and Discussion}

\subsection{Determination of $\mathrm{p} K_{\mathrm{a}}$ values}

Pyranoanthocyanin derivatives JO3, JO9, JO10 and AF3 were fully characterized with respect to their $\mathrm{p} K_{\mathrm{a}}$ values. All the other compounds had been previously characterized with respect to their aqueous equilibria and the respective $\mathrm{p} K_{\mathrm{a}}$ values are summarized in Table 1 . The UV-Vis spectra of each compound were obtained for the $\mathrm{pH}$ range between 1 and 12. The prototropic equilibria and the related spectroscopic changes are quite relevant in the context of the application of this family of compounds in DSSCs, as previously discussed. (Pinto et al., 2019b) Upon increasing the $\mathrm{pH}$, there are observable changes in the absorbance spectrum and intensity that impact the light absorption by the dye. Additionally, there is a change in the protonation degree that affects its performance as an electron-donor. Since pyranoanthocyanins exhibit no apparent hydration (Pina et al., 2012), only acidbase equilibria were considered, meaning that the cation only undergoes protonation/deprotonation reactions. (Cruz et al., 2010; Oliveira et al., 2009) In the case of the polyprotic compounds, the global sequential deprotonation process (Scheme 3) can be accounted for by Eqs.(1)-(4) [see Supplementary Information] .

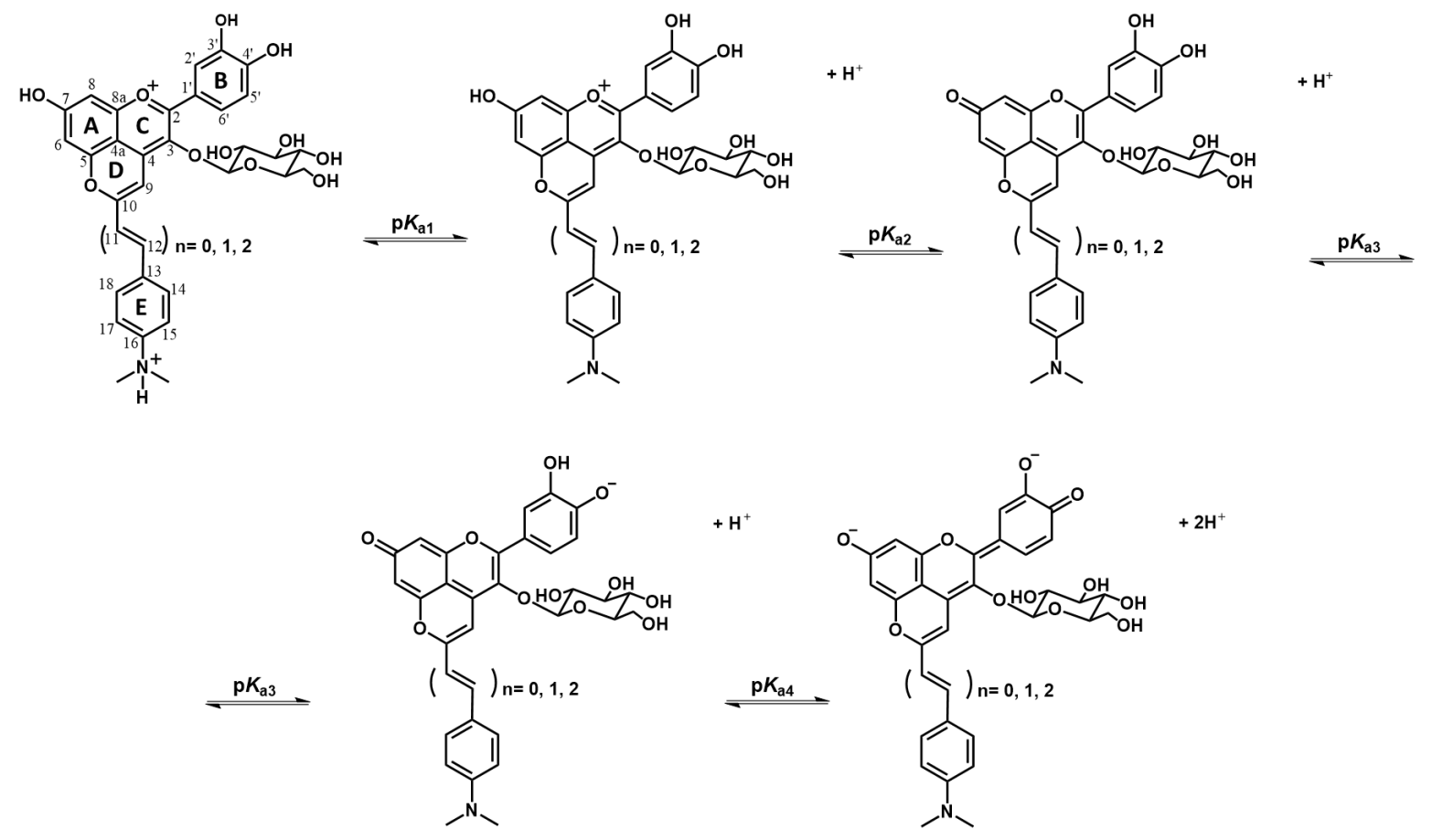

Scheme 3. General representation of the sequential proton transfer equilibria of the dimethylamino-derived pyranoanthocyanins in aqueous solutions in the range $1<\mathrm{pH}<12$. 
Inspection of the results for compound JO3 in Figure 1 shows the potential existence of four acidbase equilibria (see Scheme 3). Since the acidity constants are sufficiently different, isosbestic points can be observed in restricted $\mathrm{pH}$ ranges (see Fig. 1a to Fig. 1d) and the mathematical fit of the absorption data was consistent with four $\mathrm{p} K_{\mathrm{a}}$ values (Fig. 1e). Nevertheless, spectrophotometric determinations of the acidity constants of polyprotic acids are subject to a rather large uncertainty, with an estimated error of $\pm 0.1 \mathrm{pH}$ units in the present case. The more acidic $\mathrm{p} K_{\mathrm{a}}\left[\mathrm{p} K_{\mathrm{a} 1}=0.5\right]$ (Fig. 1a) can be attributed to deprotonation of the dimethylammonium group, as observed for other aminobased pyranoanthocyanin derivatives. (Oliveira et al., 2017) With the increase of pH to 5.9 (Fig. 1b), a decrease in the absorbance is observed, together with a hypsochromic shift and the appearance of a shoulder at $480 \mathrm{~nm}$. The calculated $\mathrm{p} K_{\mathrm{a} 2}=4.4$ is assigned to the deprotonation of the 7-hydroxy substituent, as observed in many analogous flavylium cation derivatives. (Pina et al., 2012) The $\mathrm{p} K_{\mathrm{a} 3}=8.1$ (Fig. 1c) is thus attributed to deprotonation of one of the hydroxy groups in ring B, probably that at the 4'-position, giving the more highly conjugated base (see Scheme 3). Finally, $\mathrm{p} K_{\mathrm{a} 4}=9.9$ (Fig. 1d) should correspond to deprotonation of the last hydroxyl substituent.

Identical studies were performed for compounds JO9, JO10 and AF3 (see Supporting Information, Figures $\mathrm{S} 1$ to $\mathrm{S} 3$ ), and the respective $\mathrm{p} K_{\mathrm{a}}$ values, together with previously published values for compounds LC1 (Sousa et al., 2017), JO11, JO12 and JO13 (Oliveira et al., 2017), are collected in Table 1. 


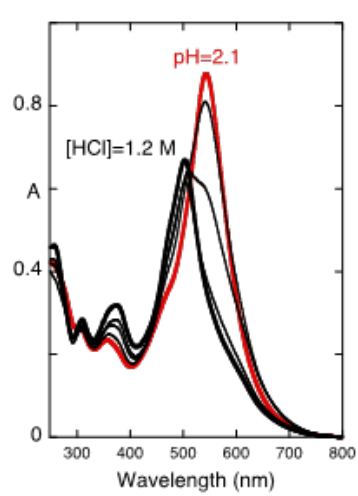

(a)

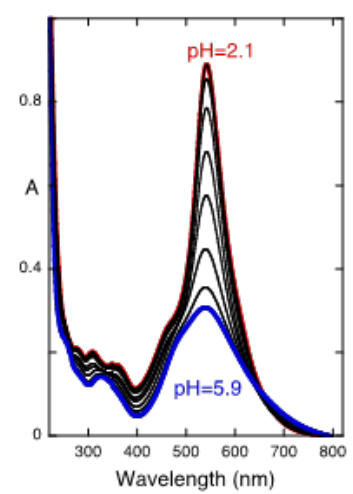

(b)

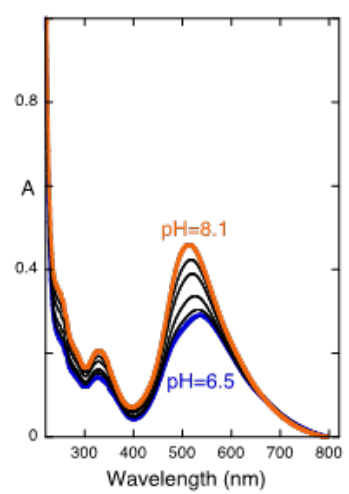

(c)

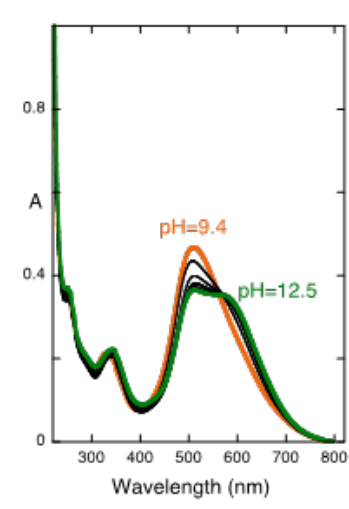

(d)

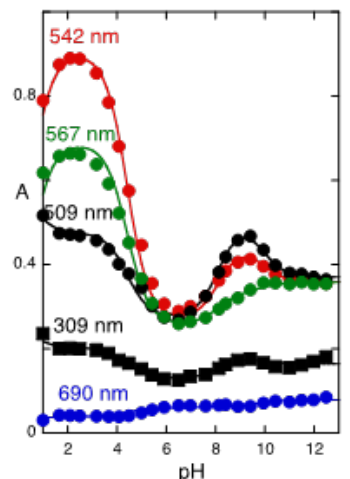

(e)

Figure 1. $\mathrm{pH}$ dependent spectral variations of compound $\mathbf{J O 3}$ in aqueous solution: a) $1.2 \mathrm{M} \mathrm{HCl}<\mathrm{pH}<2.1$; b) $2.1<\mathrm{pH}<5.9 ;$ c) $6.5<\mathrm{pH}<8.1$;) $9.4<\mathrm{pH}<12.5$; e) $\mathrm{p} K_{\mathrm{a}}$ fits: $K_{\mathrm{a} 1}=0.5 ; \mathrm{p} K_{\mathrm{a} 2}=4.4 ; \mathrm{p} K_{\mathrm{a} 3}=8.1 ; \mathrm{p} K_{\mathrm{a} 4}=9.9$.

Table 1. Protonation constants of the compounds studied in this work in aqueous solution. Estimated error $\pm 0.1 \mathrm{pH}$ units.

\begin{tabular}{cccccc}
\hline Compound & $\mathbf{p} \boldsymbol{K}_{\mathrm{a} 1}$ & $\mathbf{p} \boldsymbol{K}_{\mathrm{a} 2}$ & $\mathbf{p} \boldsymbol{K}_{\mathbf{a} 3}$ & $\mathbf{p} \boldsymbol{K}_{\mathbf{a} 4}$ & Reference \\
\hline LC1 $^{\text {a }}$ & $<1$ & 3.6 & 8.4 & $\mathrm{~b}$ & (Sousa et al., 2017) \\
JO3 & 0.5 & 4.4 & 8.1 & 9.9 & This work \\
JO9 & 1.9 & 3.8 & 7.9 & 9.6 & This work \\
JO10 & 2.15 & 4.2 & 8.1 & 9.9 & This work \\
JO11 & $<1$ & 5.4 & 9.5 & - & (Oliveira et al., 2017) \\
JO12 & 1.1 & 4.8 & 8.9 & - & (Oliveira et al., 2017) \\
JO13 & 2.4 & 2.7 & 9.8 & - & (Oliveira et al., 2017)
\end{tabular}


${ }^{a}$ protonation constants determined in water/ethanol (75:25) solution.

${ }^{\mathrm{b}}$ could not be determined due to precipitation.

\subsection{Impact of the $\pi$-bridge and of dual mode binding on the absorption spectral range}

A key structural difference within the groups of pigments studied is the type of linkage connecting the pyrano ring and the 4-(dimethylamino)-cinnamyl group. In dyes LC1, JO3, JO11 and AF3 the two moieties are directly linked through a C-C bond, while in pigments JO9 and JO12 the connection is made through a vinylene linkage and in pigments $\mathbf{J O 1 0}$ and JO13 through a butadienylidene bridge. These structural features confer different colors on these dyes in solution, as well as different acidity constants as shown in Table 1.

An important additional structural variation of the pyranoanthocyanins studied is the substitution pattern in ring B. For LC1, JO3, JO9 and JO10, ring B possesses a catechol unit (pyranocyanidin derivatives), while in compounds JO11, JO12 and JO13 ring B possesses a single -OH at position 4' with two adjacent methoxy groups at positions $3^{\prime}$ and 5' (pyranomalvidin (oenin) derivatives). Compound AF3, on the other hand, has no additional substituents in ring B (Scheme 4).

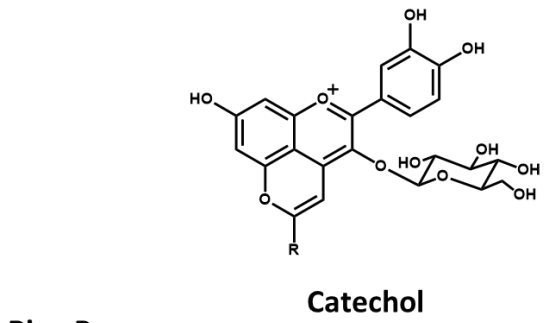

Ring $\mathbf{B}=$

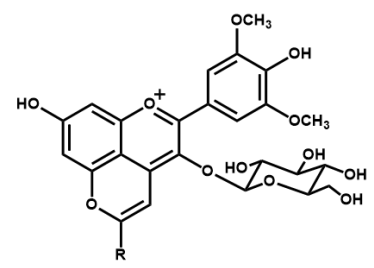

Dimethoxy, Hydroxy

(Malvidin (oenin))

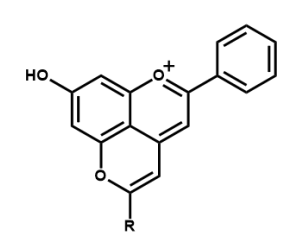

(no substitution)

Scheme 4. Structural features of the pyranoanthocyanin and pyranoflavylium compounds.

As previously mentioned, changes in $\mathrm{pH}$ can drastically affect the absorption spectral range and intensity of these dyes, as well as their charge separation ability. The different structural features in these families of compounds were specifically chosen in order to elucidate their role in the type of anchoring of the dye to $\mathrm{TiO}_{2}$ and the impact on charge transfer as reflected in the efficiencies of the final devices. Two adsorption conditions were compared using a $0.5 \mathrm{mM}$ solutions of the dye in ethanol and in ethanol containing $10 \mu \mathrm{L}$ added $\mathrm{HClO}_{4}$. This addition of acid can potentially affect the protonation degree of the different dyes according to their respective $\mathrm{p} K_{\mathrm{a}}$ values which might then impact the binding of the different species in equilibrium to $\mathrm{TiO}_{2}$. For compounds $\mathbf{J O 1 0}$ and $\mathbf{J O 1 3}$ 
in ethanol solution, acidification results in a noticeable blue-shift of the absorption maximum [by 121 and $128 \mathrm{~nm}$, for $\mathbf{J O 1 0}$ and $\mathbf{J O 1 3}$, respectively] (Figure 2), spectral shift not observed for the other compounds (Table S1). This result is quite interesting since it allows identification of the species present in the dye solution prior to adsorption onto $\mathrm{TiO}_{2}$. Comparing the spectra collected for compound JO10 with the spectra determined during the $\mathrm{p} K_{\mathrm{a}}$ determinations in aqueous medium (Figure S2), permits identification of the species present, despite the obvious spectral shift due to solvatochromic effect. (Pina et al., 2012) Thus, in ethanol the majority of the molecules are in the $\mathrm{AH}^{+}$and $\mathrm{A}$ forms, whereas upon acidification of the ethanol the equilibrium shifts towards formation of the species $\mathrm{AH}^{2+}$ (see Scheme 3) in which the dimethylamine group is protonated. The same behavior was observed for compound JO13. In contrast, the same comparison for compounds JO3 and JO9 (with shorter $\pi$-bridges) shows that most of the molecules are in the $\mathrm{AH}^{+}$and $\mathrm{A}$ forms in both acidic and non-acidic ethanol solutions, i.e, protonation of the dimethylamine group is not significant. These results are consistent with the $\mathrm{p} K_{\mathrm{a} 1}$ values determined for these compounds (Table 1). Since the dimethylamine groups of compounds $\mathbf{J O 1 0}$ and $\mathbf{J O 1 3}$ are more basic, they are more readily protonated than the other compounds, resulting in the observed blue-shift.
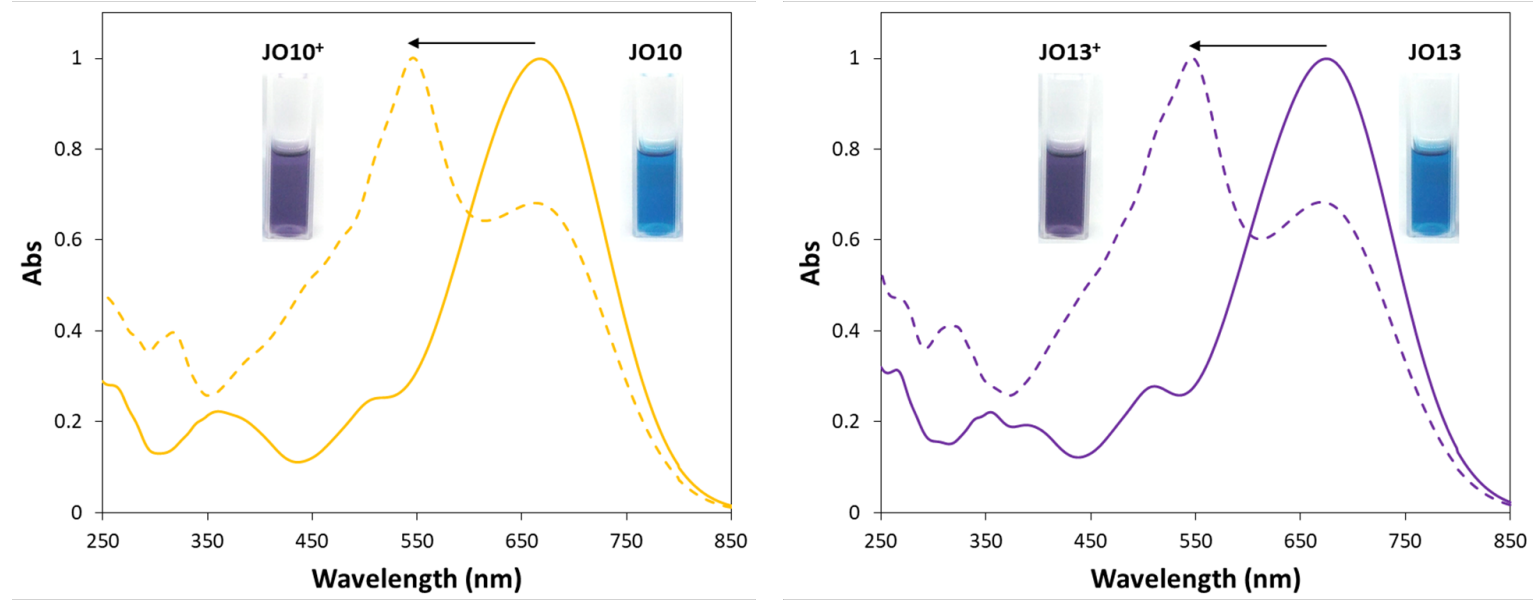

Figure 2. Normalized absorption spectra of solutions based on dyes JO10 (left) and JO13 (right), emphasizing the blue-shift in the peak maximum between ethanol (full line) and acidified ethanol (dotted line) solutions of the dyes.

A general trend was verified upon adsorption of the dyes from ethanol and acidified ethanol solutions onto the $\mathrm{TiO}_{2}$ films. Overall, for most of the compounds, a blue-shift in the absorption spectral maximum was observed in comparison with that of the dye in the original solution (Table S1), again with no significant qualitative changes in the spectra. The most striking result was, however, the difference in the final color for compounds $\mathbf{J O 1 2}$ and JO13 resulting from adsorption from ethanol 
vs. acidified ethanol. As shown in Figure 3, for the same compound the presence of acid in the adsorption solution, causes drastic changes in the color of the resulting film. For dyes JO12 and JO13, two colors can be clearly differentiated, depending on the presence or absence of acid in the solution, i.e, blue for the adsorption from ethanol and red for the adsorption from acidified ethanol solution.

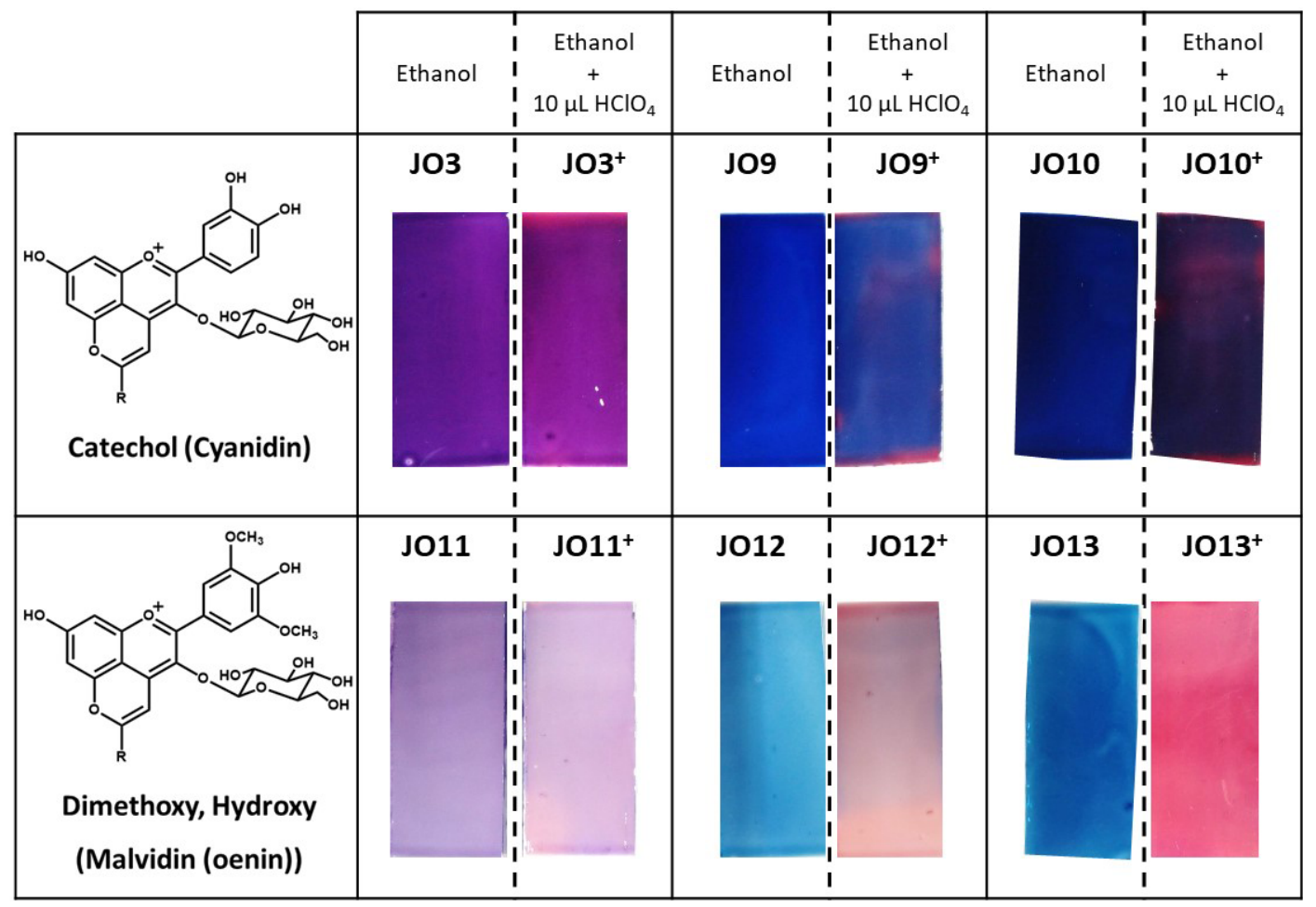

Figure 3. Color photographs of the glass slides after adsorption of the dyes onto a titanium oxide film from an ethanol solution of the dyes $(0.5 \mathrm{mM})$ or from an acidified ethanol solution of the dyes $(0.5 \mathrm{mM})$.

From comparison with the absorption profiles from the $\mathrm{p} K_{\mathrm{a}}$ determinations, it is possible to infer that the red color (Figure 3) corresponds to an absorption spectral range identical to that of the species $\mathrm{AH}^{2+}$ (e.g., see Fig. 1a). Red is the color expected when the lone electron pair of the amine nitrogen is involved in a sigma-donating bond, i.e., a red color serves as a spectral signature of binding of the compound to the surface of $\mathrm{TiO}_{2}$ via the dimethylamine group. In the case of the blue films, the anchoring moiety must be one or more of the available -OH groups, as is usually the case for these compounds. (Pinto et al., 2019b) The interesting aspect is that, upon addition of acid to the ethanol solution, anchoring through the amine group becomes favored. Since surface $-\mathrm{O}^{-}$groups and the hydroxyl substituents of the dye are more basic than the dimethylamine substituent, the hydroxy groups and the surface sites will be protonated, favoring hydrogen-bond-mediated anchoring of the 
dye to the titanium dioxide surface via the dimethylamine substituent rather than via the OH groups

of ring B. This will consequently result in the observed red color, corresponding to an absorbance that resembles that of the $\mathrm{AH}^{2+}$ species observed in solution. In fact, upon closer inspection, even the films of compounds JO9 and JO10 exhibit both red and blue colors (Figure 3) when adsorbed from acidified ethanol.

Concerning ring $\mathrm{B}$ substitution pattern of the pyranoanthocyanin (derived from cyanidin vs. malvidin), adsorption of $\mathbf{J O 1 0}$ from acidified ethanol solution leads to a mixture of dimethylamine and $-\mathrm{O}^{-}$anchoring to $\mathrm{TiO}_{2}$, indicated by the strong blue color of the films, while for $\mathbf{J O 1 3}$ there is a clear dominance of dimethylamine anchoring (only red color). This leads to the conclusion that the presence of the catechol moiety in ring $\mathrm{B}$ can favor the binding through $-\mathrm{OH}$. In the malvidin derivatives JO12 and JO13, however, the presence of the methoxy groups flanking the 4'-OH group can sterically hinder the complexation to $\mathrm{TiO}_{2}$, thus favoring anchoring through the dimethylamine group.

\subsection{Optical properties of the assembled DSSCs and impact on the IPCE}

The results for the dyes adsorbed onto $\mathrm{TiO}_{2}$ films discussed in the previous section provide a preliminary assessment of what to expect in terms of the dye- $\mathrm{TiO}_{2}$ interaction. Nevertheless, when considering the solar cell device as a whole, the interactions between the dye- $\mathrm{TiO}_{2}$ complex and the other components of the system have important consequences for the overall energetics of the cell. (Hagfeldt et al., 2010) One of such component is the electrolyte. As already discussed, these compounds, which have prototropic equilibria, are sensitive to alterations of the local $\mathrm{pH}$ of the environment and to the ionic strength of the medium. (Oliveira et al., 2017; Pinto et al., 2019b) Hence, when exposed to the electrolyte in a final assembled cell, further changes might occur, not accounted for in terms of $\mathrm{pH}$ alone. In order to gain insight into the impact of these changes on the optical properties and how they are ultimately reflected in the external quantum efficiency of the assembled devices, a comparison was performed between diffuse reflectance spectroscopy and incident photonto-current conversion efficiency (IPCE).

The results of diffuse reflectance spectroscopy of the assembled cells, shown in Figure 4, revealed interesting results. An increase in conjugation results in extended absorbance towards longer wavelengths. This same tendency was also verified in the cells prepared by adsorption of the dye under acidic conditions. As verified in the previous section, for compounds JO12 and JO13 the 
resulting film was red, indicating adsorption via the dimethylamine group. Nonetheless, despite the acidic conditions employed in the adsorption, once incorporated into the assembled cells, the compounds show an intense longer-wavelength absorbance. This may be an indication that contact with the acetonitrile-based electrolyte and the high ionic strength of the concentrated LiI electrolyte (Furube et al., 2005) can promote rearrangement from anchoring via the dimethylamine group to anchoring through phenol groups.

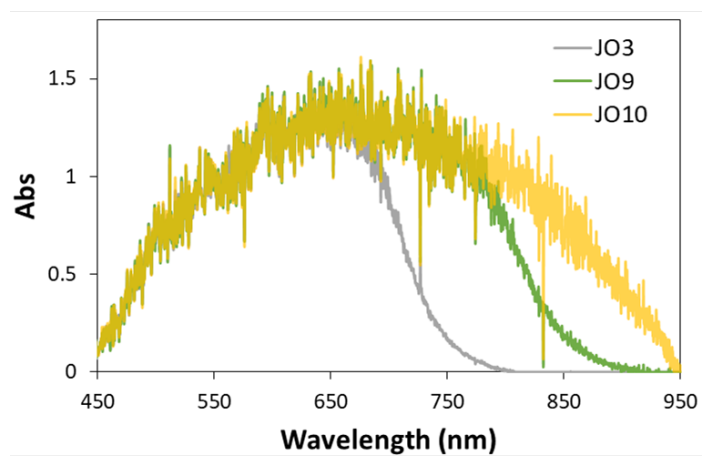

(a)

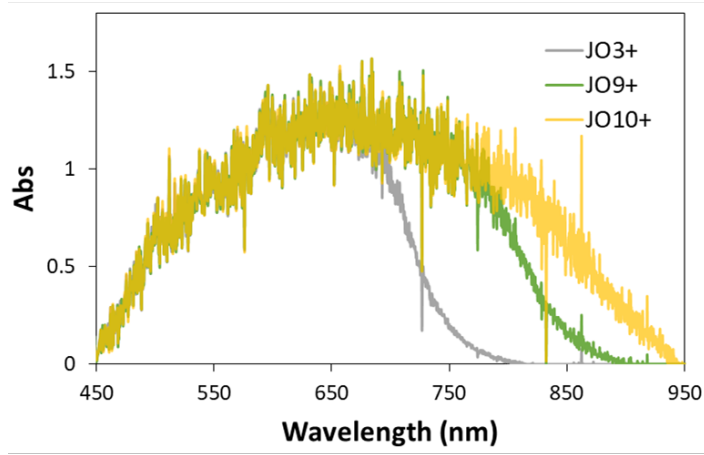

(c)

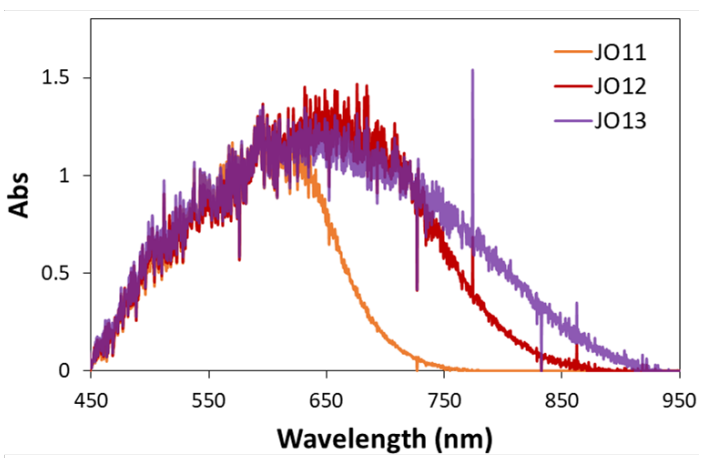

(b)

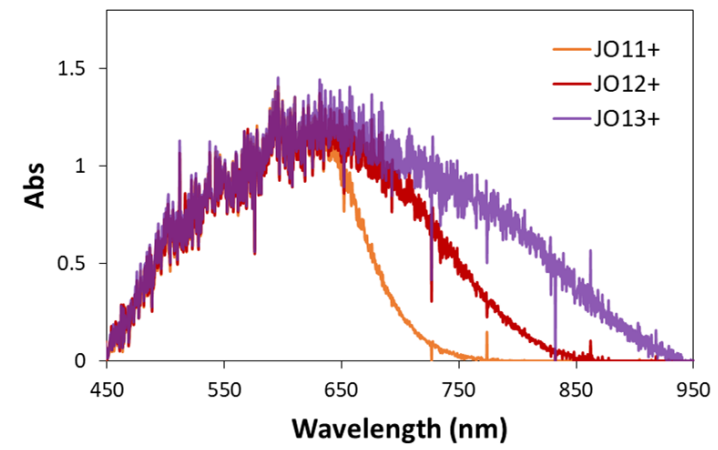

(d)

Figure 4. Absorption spectra measured in diffuse reflectance spectroscopy geometry for DSSCs based on compounds JO3, JO9 and JO10 (a) and JO11, JO12 and JO13 (b) adsorbed from $0.5 \mathrm{mM}$ ethanol solutions of the dyes; absorption spectra measured in diffuse reflectance spectroscopy geometry of DSSCs based on dyes $\mathbf{J O 3}^{+}, \mathbf{J O 9}^{+}$and $\mathrm{JO10}^{+}$(c) and $\mathrm{JO11}^{+}, \mathbf{J O 1 2}^{+}$and $\mathrm{JO13}^{+}$(d) adsorbed from acidified $0.5 \mathrm{mM}$ ethanol solutions of the dyes.

This hypothesis is supported by the IPCE results (Figure S8). For all compounds there is a clear contribution to the current production from absorption at wavelengths above $550 \mathrm{~nm}$. This is an indication of adsorption via $-\mathrm{OH}$ units, since, as already discussed, anchoring via the dimethylamine groups results in hypsochromic shifts. For devices $\mathbf{J O 1 0}^{+}, \mathbf{J O 1 2}^{+}$and $\mathbf{J O 1 3}^{+}$(adsorption from acidic solution), however, a contribution at shorter wavelengths was also verified (Figure S8). This can be an indication of the existence of residual anchoring via the dimethylamine group. In these cases, this additional anchorage can eventually be advantageous, increasing the wavelength range contributing 
to current production in these specific devices, with a corresponding increase in the overall efficiency of these cells.

\subsection{Photovoltaic performance of the DSSCs}

The photocurrent density-voltage plots for DSSCs assembled with the pyranoflavylium dyes LC1 AF3 are shown in Figure 5. Analysis of these data allowed determination of the short circuit current density $\left(\mathrm{J}_{\mathrm{SC}}\right)$, open circuit voltage $\left(\mathrm{V}_{\mathrm{OC}}\right)$, fill factor $(\mathrm{FF})$ and overall conversion efficiency $(\eta)$, summarized in Table 2. The photovoltage generated by the cell under illumination corresponds to the difference between the Fermi level of the electron in the semiconductor and the redox potential of the electrolyte. (Grätzel, 2005) Therefore, the electrolyte composition used is known to have a direct impact on the $\mathrm{V}_{\mathrm{OC}}$ values obtained for the devices. Lithium is known to act as a $\mathrm{TiO}_{2}$ Fermi level stabilizer, thus moving the $\mathrm{TiO}_{2}$ conduction band towards more positive potentials, usually resulting in higher $\mathrm{J}_{\mathrm{SC}}$ values in detriment of $\mathrm{V}_{\mathrm{OC}}$ results. (Jennings and Wang, 2010) Opposite to the effect of the lithium ion on the conduction band of $\mathrm{TiO}_{2}$, pyridine derivatives, such as tert-butylpyridine, are known to elevate the energy level of the lower end of the $\mathrm{TiO}_{2}$ conduction band, resulting in higher $\mathrm{V}_{\text {OC. }}$. Thus, the electrolyte composition used is determinant for the $\mathrm{V}_{\mathrm{OC}}$ values obtained. As previously shown (Pinto et al., 2019b), in this family of compounds the addition of pyridine derivatives, despite resulting in higher $\mathrm{V}_{\mathrm{OC}}$ values, showed a tremendous negative impact in the $\mathrm{J}_{\mathrm{SC}}$ produced by the devices, resulting in ca.10-fold decrease in efficiency. Therefore, in this work, a lithium-based electrolyte (with no further additives) was used resulting in the low $\mathrm{V}_{\mathrm{OC}}$ values verified. 


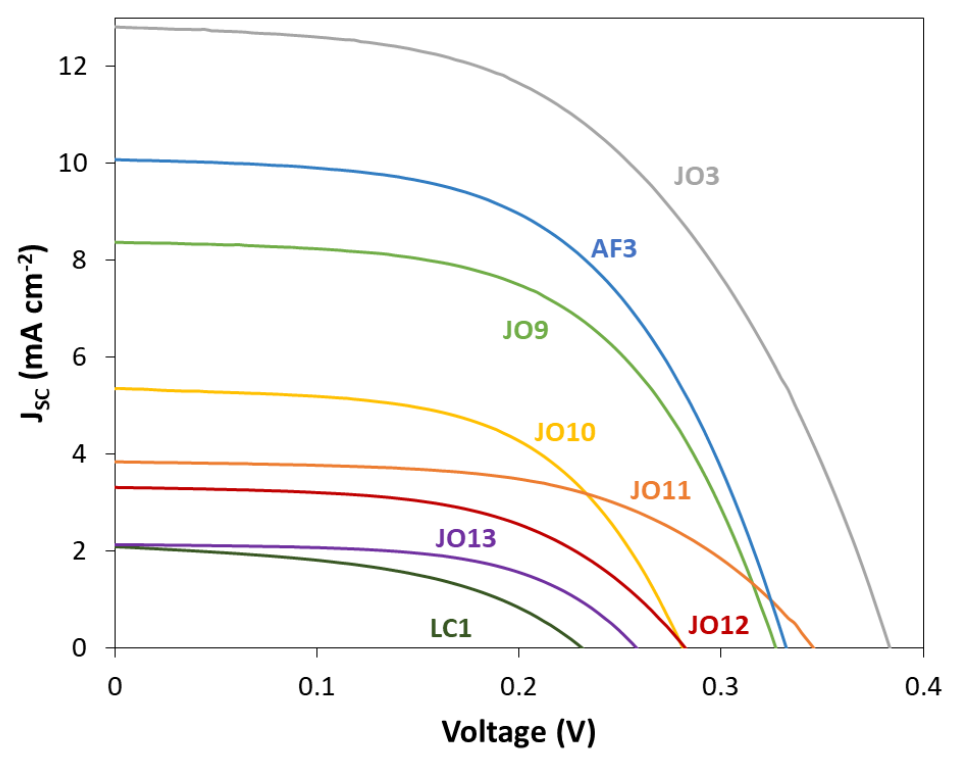

Figure 5. Current-potential curves under $100 \mathrm{~mW} \mathrm{~cm}^{-2}$ simulated AM 1.5 illumination for DSSCs based on compounds LC1 - AF3 (Scheme 2) adsorbed from 0.5 mM solutions in ethanol.

Table 2. Photovoltaic performance under $100 \mathrm{~mW} \mathrm{~cm}^{-2}$ simulated AM 1.5 illumination for DSSCs based on compounds LC1 - AF3 (Scheme 2) adsorbed from 0.5 mM solutions in ethanol.

\begin{tabular}{ccccccc}
\hline Dye & $\begin{array}{c}\mathbf{J}_{\text {SC }}(\mathbf{m A} \\
\left.\mathbf{c m}^{-2}\right)\end{array}$ & $\begin{array}{c}\mathbf{V}_{\mathbf{O C}} \\
(\mathbf{m V})\end{array}$ & $\begin{array}{c}\mathbf{J}_{\mathbf{m a x}}(\mathbf{m A} \\
\left.\mathbf{c m}^{-\mathbf{2}}\right)\end{array}$ & $\begin{array}{c}\mathbf{V}_{\max } \\
(\mathbf{m V})\end{array}$ & $\mathbf{F F}$ & $\boldsymbol{\eta}(\mathbf{\%})$ \\
\hline LC1 & 2.08 & 230 & 1.43 & 155 & 0.47 & 0.23 \\
JO3 & 12.78 & 383 & 10.10 & 252 & 0.52 & 2.55 \\
JO9 & 8.36 & 326 & 6.84 & 229 & 0.57 & 1.55 \\
JO10 & 5.33 & 280 & 4.34 & 198 & 0.57 & 0.86 \\
JO11 & 3.83 & 345 & 3.11 & 238 & 0.56 & 0.75 \\
JO12 & 3.30 & 281 & 2.65 & 193 & 0.55 & 0.52 \\
JO13 & 2.13 & 258 & 1.73 & 184 & 0.58 & 0.32 \\
AF3 & 10.06 & 332 & 8.16 & 229 & 0.56 & 1.88 \\
\hline
\end{tabular}

The molecular structure of the compounds also significantly affects the values obtained. An increase in the number of $\mathrm{C}=\mathrm{C}$ bonds, from compounds $\mathbf{J O 3}$ to $\mathbf{J O 1 0}$ (cyanidin series) or $\mathbf{J O 1 1}$ to $\mathbf{J O 1 3}$ (oenin series) leads to a decrease in the values of both $\mathrm{J}_{\mathrm{SC}}$ and $\mathrm{V}_{\mathrm{OC}}$ (see Figure S4). Compounds JO3 and JO11, in which the pyrano unit is linked to the 4-(dimethylamino)-cinnamyl moiety through a single $\mathrm{C}-\mathrm{C}$ bond, present (within the cyanidin and oenin series, respectively) the highest $\mathrm{J}_{\mathrm{SC}}$ and $\mathrm{V}_{\mathrm{OC}}$ values, with efficiencies of 2.55 and $0.75 \%$, respectively. For compounds JO9 and JO12, with a vinylene linkage connecting the two moieties, and compounds JO10 and JO13, with a butadienylidene linkage, there was a decrease in $\mathrm{J}_{\mathrm{SC}}$ and $\mathrm{V}_{\mathrm{OC}}$ from 8.36 to $5.33 \mathrm{~mA} \mathrm{~cm}^{-2}$ and 326 to 
$280 \mathrm{mV}$ for compounds $\mathbf{J O 9}$ and $\mathbf{J O 1 0}$ and from 3.30 to $2.12 \mathrm{~mA} \mathrm{~cm}^{-2}$ and 281 to $258 \mathrm{mV}$ for compounds JO12 and JO13, respectively. This ultimately leads to a decrease in the overall efficiency from 1.55 to $0.86 \%$ for compounds $\mathbf{J O 9}$ and $\mathbf{J O 1 0}$ and 0.52 to $0.32 \%$ for compounds $\mathbf{J O 1 2}$ and JO13. Despite the red-shift and broadening of the spectra in the visible spectral region with the increase in conjugation for these compounds (Figure S5), this does not translate into an increase in the overall efficiency of the DSSCs. Since the dimethylamine moiety is the electron-donor group of the molecule, it is essential that its electron pair is available for conjugation throughout the molecule in order to produce the desired D- $\pi$-A molecular ensemble. The increase in conjugation results in an increase in the value of $\mathrm{p} K_{\mathrm{a} 1}$ (see Table 1), which means that the molecules become harder to deprotonate. This will consequently make the dimethylamine electron pair less available to participate in conjugation, resulting in a reduced electron-donor ability of the dimethylamine moiety that ultimately results in lower efficiencies. The increase in conjugation translates into a less rigid dye molecule, which leads to lower PCE's (see Figure S6) and possibly increased energy losses due to competition between electron injection and vibrationally-induced non-radiative decay. (Zhang et al., 2019) Thus, a greater degree of involvement of the dimethylamine electron pair in conjugation and a more rigid geometric structure of the sensitizer are preferable in order to obtain faster electron injection, minimize energy losses and increase the overall DSSC performance.

Compounds JO3, JO9 and JO10, which are cyanidin derivatives, consistently had higher efficiencies than their oenin analogues JO11, JO12 and JO13 (Table 2). The higher $\mathrm{J}_{\mathrm{SC}}$ and $\mathrm{V}_{\mathrm{OC}}$ values obtained for the cyanidin derivatives can be partially attributed to the fact that the cyanidin derivatives exhibited more intense absorption spectra when adsorbed onto $\mathrm{TiO}_{2}$ (Table S1), as also indicated by diffuse reflectance spectra of the assembled cells, Figure 6 (a), (b) and (c). Although more efficient absorption of light does not necessarily imply better DSSC performance, in this case, the higher absorbances for the cyanidin derivatives were accompanied by higher photocurrents, which translated in higher IPCE results [Figure 6 (d), (e) and (f)]. This suggests that the presence of electron-donor methoxy groups in the vicinity of the 4'-OH group involved in anchoring to $\mathrm{TiO}_{2}$ can possibly affect the electron injection ability of the oenin-derived compounds. Alternatively, the steric hindrance of these methoxy groups may be so great that anchoring through the 4'-OH group becomes less effective. Since both diffuse reflectance spectroscopy and IPCE indicate anchoring via -OH groups, anchoring via the 7-OH group must also be considered as a possibility. In order to assess the effectiveness of anchoring through the 7-OH group, compound AF3 was studied. Compound AF3 has a structure similar to that of compound JO11 but lacks the substituents in ring B and the sugar moiety. Despite these structural differences, compound AF3 presents an overall efficiency of $1.88 \%$, which is $\sim 2.5$ 
fold higher than the efficiency of compound JO11. This result is due mainly to the $\mathrm{J}_{\mathrm{SC}}$ of $10.06 \mathrm{~mA}$ $\mathrm{cm}^{-2}$ and suggests that the 7-OH group of pyranoflavylium derivatives is indeed able to provide efficient anchoring to $\mathrm{TiO}_{2}$. Furthermore, anchorage via the 7-OH group seems to be more favorable than anchorage through a sterically hindered 4'-OH group, such as in compound JO11.

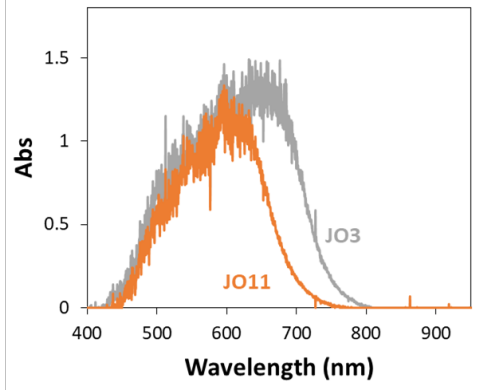

(a)

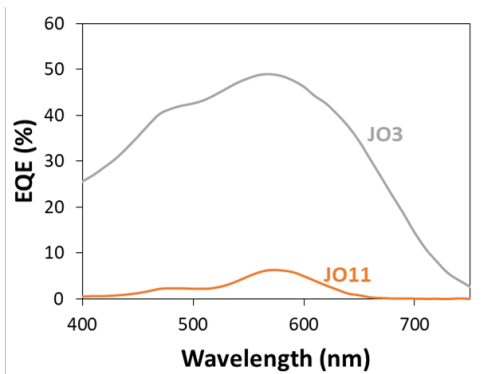

(d)

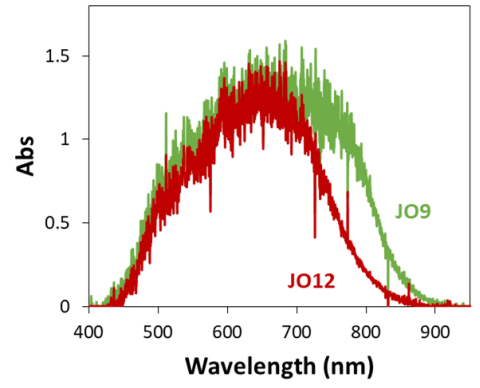

(b)

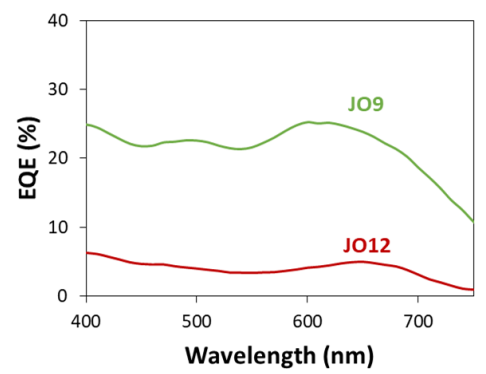

(e)

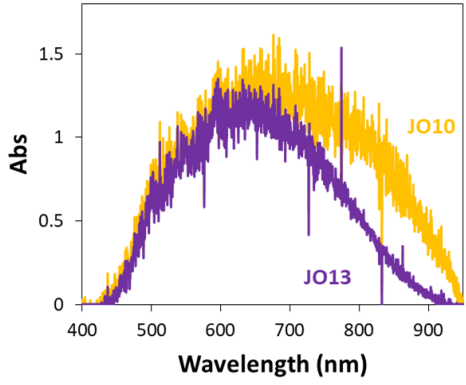

(c)

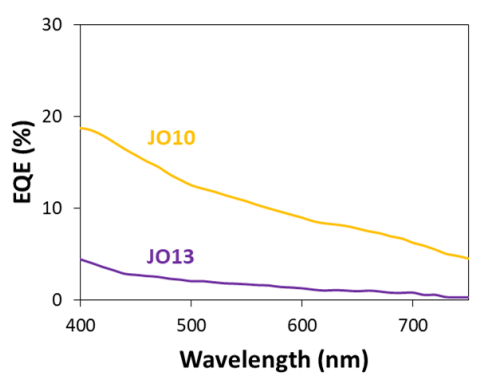

(f)

Figure 6. Comparison of diffuse reflectance spectra for DSSCs based on compounds JO3 and JO11 (a), JO9 and $\mathbf{J O 1 2 ~ ( b ) ~ a n d ~} \mathbf{J O 1 0}$ and $\mathbf{J O 1 3}$ (c). Comparison of IPCE spectra for DSSCs based on compounds JO3 and JO11 (d), JO9 and JO12 (e) and JO10 and JO13 (f).

Compound JO3 was the dye that performed the best in DSSCs, with an efficiency of $2.55 \%$, while its deoxyanthocyanidin counterpart, compound LC1, was the worst performer, with an efficiency of only $0.23 \%$. The $\mathrm{J}_{\mathrm{SC}}$ of $2.08 \mathrm{~mA} \mathrm{~cm}^{-2}$ and $\mathrm{V}_{\mathrm{OC}}$ of $230 \mathrm{mV}$ for $\mathbf{L C 1}$ can be attributed to the $\sim 3$-fold decrease in absorbance relative to compound $\mathbf{J O 3}$ combined with the the huge difference in the photocurrents, that of LC1 being ca. 6-fold lower than that of JO3. This decrease in photocurrent production is clearly seen in the comparison of the IPCE spectra of the two compounds (Figure S7).

\subsubsection{Effect of acid addition on the photovoltaic properties}

As previously shown (Pinto et al., 2019b), certain additives are known to affect the Fermi level of the $\mathrm{TiO}_{2}$ conduction band. One such phenomenon, as already mentioned, is the addition of lithium salts or acid, which have the ability to increase the photocurrent produced by the cells. This increase is, 
however, usually accompanied by a decrease in the photovoltage produced, as shown in the results presented in Figure 7 and Table 3. This same trade-off phenomenon between $\mathrm{J}_{\mathrm{SC}}$ and $\mathrm{V}_{\mathrm{OC}}$ was verified for the majority of the compounds. Despite the decrease in absorption for some of the compounds (Table 2), most of them showed an increase in $\mathrm{J}_{\mathrm{SC}}$, which means that the addition of acid resulted in an improvement in the PCE that was significant enough to affect the final cell efficiency positively (Figure S8).

The most striking improvement was verified for compound $\mathbf{L C 1}$. Addition of $\mathrm{HClO}_{4}\left(\mathbf{L C 1}^{+}\right)$resulted in a ca. 5-fold increase in the photocurrent from 2.08 to $10.63 \mathrm{~mA} \mathrm{~cm}{ }^{-2}$ and an increase in the photovoltage from 230 to $308 \mathrm{mV}$. This led to an increase of the overall efficiency from 0.23 to $1.65 \%$ for samples $\mathbf{L C 1}$ and $\mathbf{L C 1}^{+}$, respectively (Figure S9).

Sample $\mathbf{J O 3}^{+}$, on the other hand, was the only dye that, despite an increase in $\mathrm{J}_{\mathrm{SC}}$ (from 12.78 to 15.51 $\mathrm{mA} \mathrm{cm}{ }^{-2}$, for samples $\mathbf{J O 3}$ and $\mathbf{J O 3}^{+}$, respectively), showed a decrease in the final efficiency (from 2.55 to $2.33 \%$ ) due to a decrease in $\mathrm{V}_{O C}$ and the fill factor (FF) measured for samples $\mathbf{~} \mathbf{O O}$ and $\mathbf{J O 3}^{+}$, respectively. Under these same conditions, the less-substituted, readily synthesized compound $\mathbf{A F 3}^{+}$ attained a final efficiency of $2.34 \%$, a result similar to the overall best performing dye $\mathbf{J O 3}^{+}$.

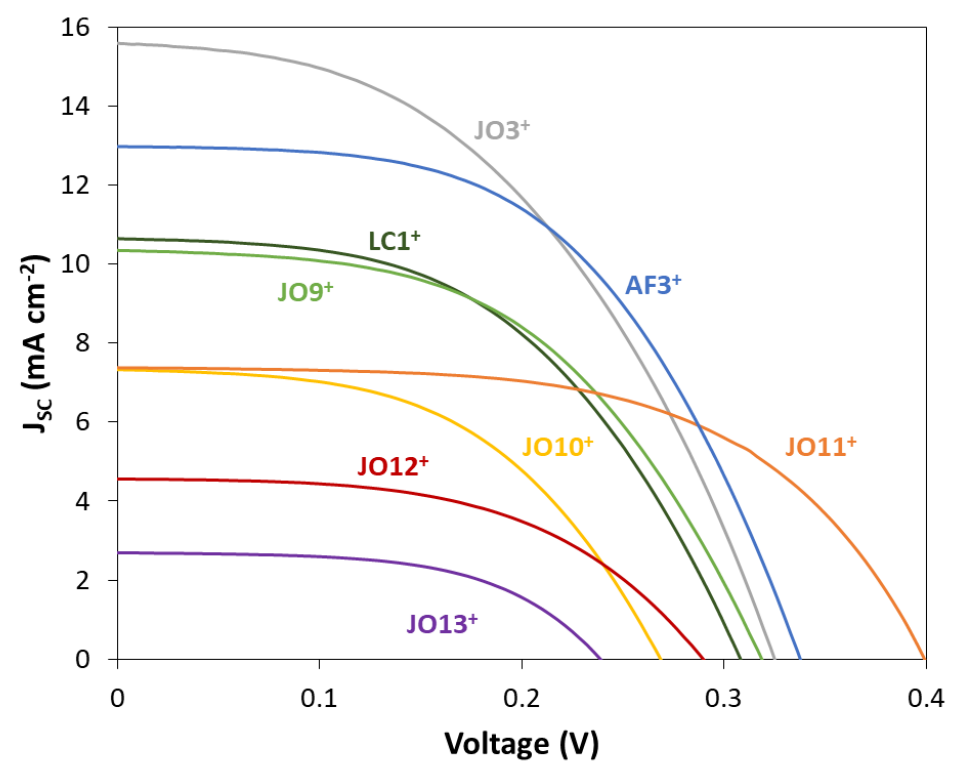

Figure 7. Current-potential curves under $100 \mathrm{~mW} \mathrm{~cm}^{-2}$ simulated AM 1.5 illumination for DSSCs based on compounds LC1 - AF3 (Scheme 2) in $0.50 \mathrm{mM}$ solution in ethanol containing $10 \mu \mathrm{L} \mathrm{HClO}_{4}$, 
Table 3. Photovoltaic performance under $100 \mathrm{~mW} \mathrm{~cm}^{-2}$ simulated AM 1.5 illumination. of DSSCs based on compounds LC1 - AF3 in $0.50 \mathrm{mM}$ solution in ethanol containing $10 \mu \mathrm{L} \mathrm{HClO}_{4}$,

\begin{tabular}{ccccccc}
\hline Dye & $\begin{array}{c}\mathbf{J}_{\mathbf{S C}}(\mathbf{m A} \\
\left.\mathbf{c m}^{-2}\right)\end{array}$ & $\begin{array}{c}\mathbf{V}_{\mathbf{O C}} \\
(\mathbf{m V})\end{array}$ & $\begin{array}{c}\mathbf{J}_{\mathbf{m a x}}(\mathbf{m A} \\
\left.\mathbf{c m}^{-2}\right)\end{array}$ & $\begin{array}{c}\mathbf{V}_{\max } \\
(\mathbf{m V})\end{array}$ & $\mathbf{F F}$ & $\boldsymbol{\eta}(\mathbf{\%})$ \\
\hline LC1+ & 10.63 & 308 & 8.27 & 199 & 0.50 & 1.65 \\
$\mathbf{J O 3 +}$ & 15.51 & 324 & 11.48 & 203 & 0.46 & 2.33 \\
JO9+ & 10.33 & 318 & 8.11 & 208 & 0.51 & 1.69 \\
JO10+ & 7.32 & 268 & 5.71 & 176 & 0.51 & 1.01 \\
JO11+ & 7.36 & 399 & 6.02 & 283 & 0.58 & 1.67 \\
JO12+ & 4.55 & 289 & 3.57 & 195 & 0.53 & 0.70 \\
JO13+ & 2.69 & 239 & 2.19 & 168 & 0.57 & 0.37 \\
AF3+ & 12.96 & 337 & 10.51 & 223 & 0.54 & 2.34 \\
\hline
\end{tabular}

\section{Conclusions}

The pyranoanthocyanins present in red wines were previously shown to display great potential as photosensitizers in bio-inspired DSSCs. (Pinto et al., 2019a, 2019b) In the present work, following a bio-inspired strategy, eight dimethylamino-derived pyranocyanidin- and pyranomalvidin-3-Oglucoside compounds were applied for the first time in DSSCs. Furthermore, the impact of extending the $\pi$-electron conjugation through insertion of $\mathrm{C}=\mathrm{C}$ bonds between the pyrano moiety and the dimethylamino group was studied. An overall efficiency of $2.55 \%$ was obtained for the best performing compound, 4-(dimethylamino)-cinnamyl-pyranocyanidin-3-O-glucoside (JO3). This result represents an improvement of $157 \%$ upon substitution of methoxy and hydroxy groups in ring E by a dimethylamine group (Pinto et al., 2019b), emphasizing the importance of studying even stronger dialkylamine-derived donors for DSSC applications of pyranoanthocyanin and pyranoflavylium-based dyes. Effective participation of the dialkylamine electron pair in the conjugation and a more rigid sensitizer chromophore are preferable in order to obtain faster electron injection, minimize energy losses and increase the overall DSSC performance. The results for the readily synthesized compound AF3 are particularly intriguing since, to the best of the authors' knowledge, this is the first time that an efficiency of $2.34 \%$ was achieved for a DSSC based on a dye with a single $\mathrm{OH}$ group as the anchoring unit. This suggests that, for pyranoflavylium derivatives, a 7-OH group may be sufficient to provide adequate anchoring to $\mathrm{TiO}_{2}$. The present work not only consolidates this family of compounds as highly promising candidates as dye-sensitizers in DSSC applications, but also paves the way for further study of a 'dual-point anchorage' approach to the design of new related bioinspired molecules. Furthermore, this work fills a gap usually found in the 
application of this family of compounds in DSSCs. Most works fail to fully grasp the impact of the available prototropic equilibria and the related spectroscopic changes found in this family of compounds in their performance for DSSC applications. By modifying the $\mathrm{pH}$ of the adsorption media, one can affect absorbance position and intensity, as well as the protonation degree of the molecules (which will reflect on electron donor ability and anchoring units). Only with this type of comprehensive study of the impact of the degree of protonation of the dyes in their final performance as light absorbers in the devices, one can fully conclude about their potential for energy applications.

\section{Acknowledgements}

FCT/MCTES is acknowledged for financial support through the Associate Laboratory for Green Chemistry-LAQV (UID/QUI/50006/2019), project PTDC/QEQ-QFI/1971/2014, grants PD/BD/135087/2017 (ALP), SFRH/BD/136556/2018 (VG), SFRH/BD/143309/2019 (PA), research FCT contracts (LC) and IF/00225/2015 (JO) and the Norma transitória DL57/2016 Program Contract (HC). The IPCE measurements were financed by FEDER funds through the COMPETE 2020 Programme and National Funds through FCT (Portuguese Foundation for Science and Technology) under the projects UID/CTM/50025/2019, ALTALUZ (PTDC/CTM-ENE/5125/2014). This study was financed in part by the Coordenação de Aperfeiçoamento de Pessoal de Nível Superior - Brasil (CAPES) - Finance Code 001 (GTMS), INCTCatálise (CNPq 444061/2018-5) and CNPq (FHQ research productivity fellowship and Universal grant 408181/2016-3).

\section{References}

Amić, D., Trinajstić, N., Davidović-Amić, D., 1992. Experimental and theoretical study of the styrylbenzopyrylium chromophore. J. Chem. Soc. Perkin Trans. 2 1933-1938. https://doi.org/10.1039/p29920001933

Calogero, G., Citro, I., Crupi, C., Jr., G.C., Arigò, D., Spinella, G., Bartolotta, A., Di Marco, G., 2019. Absorption spectra, thermal analysis, photoelectrochemical characterization and stability test of vegetable-based dye-sensitized solar cells. Opt. Mater. (Amst). 88, 24-29. https://doi.org/10.1016/j.optmat.2018.11.005 
Calogero, G., Citro, I., Di Marco, G., Caramori, S., Casarin, L., Bignozzi, C.A., Avó, J., Parola, A.J., Pina, F., 2017. Electronic and charge transfer properties of bio-inspired flavylium ions for applications in TiO2-based dye-sensitized solar cells. Photochem. Photobiol. Sci. 16, 1400-1414. https://doi.org/10.1039/c7pp00039a

Calogero, G., Sinopoli, A., Citro, I., Di Marco, G., Petrov, V., Diniz, A.M., Parola, a J., Pina, F., 2013. Synthetic analogues of anthocyanins as sensitizers for dye-sensitized solar cells. Photochem. Photobiol. Sci. 12, 883-94.

https://doi.org/10.1039/c3pp25347c

Chen, R., Yang, X., Tian, H., Wang, X., Hagfeldt, A., Sun, L., 2007. Effect of Tetrahydroquinoline Dyes Structure on the Performance of Organic Dye-Sensitized Solar Cells. Chem. Mater. 19, 4007-4015. https://doi.org/10.1021/cm070617g

Cherepy, N.J., Smestad, G.P., Grätzel, M., Zhang, J.Z., 1997. Ultrafast Electron Injection: Implications for a Photoelectrochemical Cell Utilizing an Anthocyanin Dye-Sensitized TiO2 Nanocrystalline Electrode. J. Phys. Chem. B 101, 9342-9351. https://doi.org/10.1021/jp972197w

Clifford, J.N., Martínez-Ferrero, E., Palomares, E., 2012. Dye mediated charge recombination dynamics in nanocrystalline $\mathrm{TiO} 2$ dye sensitized solar cells. J. Mater. Chem. 22, 12415-12422. https://doi.org/10.1039/c2jm16107a

Cruz, L., Petrov, V., Teixeira, N., Mateus, N., Pina, F., Freitas, V. de, 2010. Establishment of the Chemical Equilibria of Different Types of Pyranoanthocyanins in Aqueous Solutions: Evidence for the Formation of Aggregation in Pyranomalvidin-3-Ocoumaroylglucoside-(+)-catechin. J. Phys. Chem. B 114, 13232-13240. https://doi.org/10.1021/jp1045673

Cruz, L., Sousa, J.L.C., Marinho, A., Mateus, N., de Freitas, V., 2017. Synthesis and structural characterization of novel pyranoluteolinidin dyes. Tetrahedron Lett. 58, 159-162. https://doi.org/10.1016/j.tetlet.2016.11.123

Czerney, P., Graneß, G., Birckner, E., Vollmer, F., Rettig, W., 1995. Molecular engineering of cyanine-type fluorescent and laser dyes. J. Photochem. Photobiol. A Chem. 89, 31- 
36. https://doi.org/10.1016/1010-6030(94)04018-W

Da Silva, C.P., Pioli, R.M., Liu, L., Zheng, S., Zhang, M., Silva, G.T.D.M., Carneiro, V.M.T., Quina, F.H., 2018. Improved Synthesis of Analogues of Red Wine Pyranoanthocyanin Pigments. ACS Omega 3, 954-960. https://doi.org/10.1021/acsomega.7b01955

Furube, A., Katoh, R., Hara, K., Sato, T., Murata, S., Arakawa, H., Tachiya, M., 2005.

Lithium ion effect on electron injection from a photoexcited coumarin derivative into a TiO2nanocrystalline film investigated by visible-to-IR ultrafast spectroscopy. J. Phys. Chem. B 109, 16406-16414. https://doi.org/10.1021/jp0513263

García-Estévez, I., Cruz, L., Oliveira, J., Mateus, N., de Freitas, V., Soares, S., 2017. First evidences of interaction between pyranoanthocyanins and salivary proline-rich proteins. Food Chem. 228, 574-581. https://doi.org/10.1016/j.foodchem.2017.02.030

Grätzel, M., 2005. Solar energy conversion by dye-sensitized photovoltaic cells. Inorg. Chem. 44, 6841-6851. https://doi.org/10.1021/ic0508371

Güzel, E., Arslan, B.S., Durmaz, V., Cesur, M., Tutar, Ö.F., Sarı, T., İşleyen, M., Nebioğlu, M., Şişman, İ., 2018. Photovoltaic performance and photostability of anthocyanins, isoquinoline alkaloids and betalains as natural sensitizers for DSSCs. Sol. Energy 173, 34-41. https://doi.org/10.1016/j.solener.2018.07.048

Hagfeldt, A., Boschloo, G., Sun, L., Kloo, L., Pettersson, H., 2010. Dye-Sensitized Solar Cells. Chem. Rev. 110, 6595-6663. https://doi.org/10.1021/cr900356p

Hug, H., Bader, M., Mair, P., Glatzel, T., 2014. Biophotovoltaics: Natural pigments in dyesensitized solar cells. Appl. Energy 115, 216-225. https://doi.org/10.1016/j.apenergy.2013.10.055

Jennings, J.R., Wang, Q., 2010. Influence of Lithium Ion Concentration on Electron Injection, Transport, and Recombination in Dye-Sensitized Solar Cells. J. Phys. Chem. C 114, 1715-1724. https://doi.org/10.1021/jp9104129

Küster, F.W., Thiel, A., 1982. Tabelle per le Analisi Chimiche e Chimico-Fisiche, 12th 
edn. ed. Milano.

Mahmood, A., 2016. Triphenylamine based dyes for dye sensitized solar cells: A review. Sol. Energy 123, 127-144. https://doi.org/10.1016/j.solener.2015.11.015

Mohiuddin, O., Obaidullah, M., Sabah, C., 2018. Improvement in dye sensitized solar cells from past to present. Opt. Quantum Electron. 50, 377. https://doi.org/10.1007/s11082018-1647-1

Oliveira, J., Araújo, P., Fernandes, A., Brás, N.F., Mateus, N., Pina, F., Freitas, V. De, 2017. Influence of the structural features of amino-based pyranoanthocyanins on their acid-base equilibria in aqueous solutions. Dyes Pigments 141, 479-486. https://doi.org/10.1016/j.dyepig.2017.03.005

Oliveira, J., Araújo, P., Fernandes, A., Mateus, N., De Freitas, V., 2016a. Synthesis and Structural Characterization of Amino-Based Pyranoanthocyanins with Extended Electronic Delocalization. Synlett 27, 2459-2462. https://doi.org/10.1055/s-00351562471

Oliveira, J., Fernandes, A., De Freitas, V., 2016b. Synthesis and structural characterization by LC-MS and NMR of a new semi-natural blue amino-based pyranoanthocyanin compound. Tetrahedron Lett. 57, 1277-1281. https://doi.org/10.1016/j.tetlet.2016.02.026

Oliveira, J., Mateus, N., Silva, A.M.S., Freitas, V. De, 2009. Equilibrium Forms of Vitisin B Pigments in an Aqueous System Studied by NMR and Visible Spectroscopy. J. Phys. Chem. B 113, 11352-11358. https://doi.org/10.1021/jp904776k

Pina, F., 2014. Chemical Applications of Anthocyanins and Related Compounds. A Source of Bioinspiration. J. Agric. Food Chem. 62, 6885-6897. https://doi.org/10.1021/jf404869m

Pina, F., Melo, M.J., Laia, C.A.T., Parola, A.J., Lima, J.C., 2012. Chemistry and applications of flavylium compounds: a handful of colours. Chem. Soc. Rev. 41, 869908. 
Pinto, A.L., Cruz, L., Gomes, V., Cruz, H., Calogero, G., de Freitas, V., Pina, F., Parola, A.J., Carlos Lima, J., 2019a. Catechol versus carboxyl linkage impact on DSSC performance of synthetic pyranoflavylium salts. Dyes Pigments 170, 107577. https://doi.org/10.1016/j.dyepig.2019.107577

Pinto, A.L., Oliveira, J., Araújo, P., Calogero, G., de Freitas, V., Pina, F., Parola, A.J., Lima, J.C., 2019b. Study of the multi-equilibria of red wine colorants pyranoanthocyanins and evaluation of their potential in dye-sensitized solar cells. Sol. Energy 191, 100-108. https://doi.org/10.1016/j.solener.2019.08.050

Richhariya, G., Kumar, A., Tekasakul, P., Gupta, B., 2017. Natural dyes for dye sensitized solar cell: A review. Renew. Sustain. Energy Rev. 69, 705-718. https://doi.org/10.1016/j.rser.2016.11.198

Roque, A., Lodeiro, C., Pina, F., Maestri, M., Ballardini, R., Balzani, V., 2002. Photochromic properties of 3-methyl-substituted flavylium salts. European J. Org. Chem. 2699-2709. https://doi.org/10.1002/10990690(200208)2002:16\%3C2699::AID-EJOC2699\%3E3.0.CO;2-I

Schwarz, M., Winterhalter, P., 2003. A novel synthetic route to substituted pyranoanthocyanins with unique colour properties. Tetrahedron Lett. 44, 7583-7587. https://doi.org/10.1016/j.tetlet.2003.08.065

Sharma, K., Sharma, V., Sharma, S.S., 2018. Dye-Sensitized Solar Cells: Fundamentals and Current Status. Nanoscale Res. Lett. 6, 381. https://doi.org/10.1186/s11671-0182760-6

Sousa, J.L.C., Gomes, V., Mateus, N., Pina, F., de Freitas, V., Cruz, L., 2017. Synthesis and equilibrium multistate of new pyrano-3-deoxyanthocyanin-type pigments in aqueous solutions. Tetrahedron 73, 6021-6030.

https://doi.org/10.1016/j.tet.2017.08.051

Teng, C., Yang, X., Yang, C., Tian, H., Li, S., Wang, X., Hagfeldt, A., Sun, L., 2010. Influence of Triple Bonds as pi-Spacer Units in Metal-Free Organic Dyes for DyeSensitized Solar Cells. J. Phys. Chem. C 114, 11305-11313. 
https://doi.org/10.1021/jp102697p

Tennakone, K., Kumarasinghe, A.R., Kumara, G.R.R.A., Wijayantha, K.G.U., Sirimanne, P.M., 1997. Nanoporous TiO2 photoanode sensitized with the flower pigment cyanidin. J. Photochem. Photobiol. A Chem. 108, 193-195. https://doi.org/10.1016/S1010-6030(97)00090-7

Toan, N.D., Chiu, K.Y., Tran, T.T.H., Yang, T., Su, Y.O., 2019. Organic dyes containing nonsubstituted aryl amino moieties and azobenzene units for dye-sensitized solar cells. J. Chinese Chem. Soc. 66, 1172-1177. https://doi.org/10.1002/jccs.201900204

Tron, A., Gago, S., Mcclenaghan, N.D., Parola, A.J., Pina, F., 2016. A blue 4',7diaminoflavylium Cation Showing an Extended pH Range Stability. Phys. Chem. Chem. Phys. 18, 8920-8925. https://doi.org/10.1039/C6CP00890A

Zhang, L., Yang, X., Wang, W., Gurzadyan, G.G., Li, J., Li, X., An, J., Yu, Z., Wang, H., Cai, B., Hagfeldt, A., Sun, L., 2019. 13.6\% Efficient organic dye-sensitized solar cells by minimizing energy losses of the excited state. ACS Energy Lett. 4, 943-951. https://doi.org/10.1021/acsenergylett.9b00141 